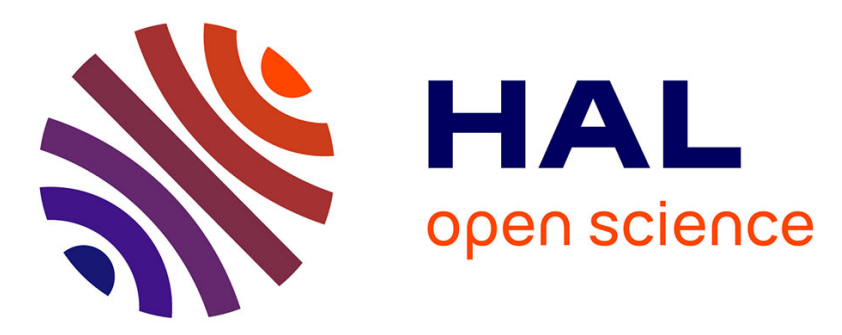

\title{
Influence of an O2 Type Oxidizing Environment on SiCf/SiC Composites: Properties/Microstructure Relationship
}

Elodie Torres, Christophe Lorrette, Patrick Weisbecker, Cédric Sauder, Céline Cabet, Brigitte Duprey, Bruno Riccetti, Laurent Briottet, Francis Rebillat

\section{To cite this version:}

Elodie Torres, Christophe Lorrette, Patrick Weisbecker, Cédric Sauder, Céline Cabet, et al.. Influence of an O2 Type Oxidizing Environment on $\mathrm{SiCf} / \mathrm{SiC}$ Composites: Properties/Microstructure Relationship. Oxidation of Metals, 2013, 80 (3-4), pp.267 - 277. 10.1007/s11085-013-9384-0 . hal-01629874

\section{HAL Id: hal-01629874 https://hal.science/hal-01629874}

Submitted on 6 Nov 2017

HAL is a multi-disciplinary open access archive for the deposit and dissemination of scientific research documents, whether they are published or not. The documents may come from teaching and research institutions in France or abroad, or from public or private research centers.
L'archive ouverte pluridisciplinaire HAL, est destinée au dépôt et à la diffusion de documents scientifiques de niveau recherche, publiés ou non, émanant des établissements d'enseignement et de recherche français ou étrangers, des laboratoires publics ou privés. 


\title{
Influence of an $\mathrm{O}_{2}$ Type Oxidizing Environment on $\mathrm{SiC}_{\mathrm{f}} / \mathrm{SiC}$ Composites: Properties/Microstructure Relationship
}

\author{
Elodie Torres $^{\mathrm{a}}$, Christophe Lorrette ${ }^{\mathrm{a}, \mathrm{b}}$, Patrick Weisbecker ${ }^{\mathrm{a}}$ \\ Cédric Sauder ${ }^{\mathrm{b}}$, Celine Cabet ${ }^{\mathrm{c}}$, Brigitte Duprey ${ }^{\mathrm{c}}$, Bruno Riccetti ${ }^{\mathrm{d}}$ \\ Laurent Briottet ${ }^{\mathrm{d}}$, Francis Rebillat ${ }^{\mathrm{a}}$ \\ ${ }^{a}$ Laboratoire des Composites Thermostructuraux, UMR 5801 CNRS-SAFRAN-CEA-UB1 \\ Domaine universitaire, 3 allée de La Boétie, 33600 Pessac, France \\ ${ }^{b}$ Commissariat à l'Energie Atomique et aux Energies Alternatives \\ CEA, DEN, DANS/DMN/SRMA, 91191 Gif-sur-Yvette, FRANCE \\ ${ }^{c}$ Commissariat à l'Energie Atomique et aux Energies Alternatives \\ CEA, DEN, DANS/DPC/SCCME, 91191 Gif-sur-Yvette, FRANCE \\ ${ }^{d}$ Commissariat à l'Energie Atomique et aux Energies Alternatives \\ CEA, LITEN, DTBH/LCTA, 38054 Grenoble, FRANCE \\ torres@lcts.u-bordeaux1.fr; christophe.lorrette@cea.fr; weisbecker@lcts.u-bordeauxl.fr; \\ cedric.sauder@cea.fr; celine.cabet@cea.fr; brigitte.duprey@cea.fr; \\ bruno.riccetti@cea.fr; laurent.briottet@cea.fr; rebillat@lcts.u-bordeauxl.fr;
}

\begin{abstract}
Ceramic matrix composites have been identified as a potential material of core structure for the $\mathrm{IV}^{\text {th }}$ generation of fission nuclear reactors. Regarding its excellent mechanical behavior in very harsh conditions (high temperature and high irradiation flux), the $\mathrm{CVI}-\mathrm{SiC}_{\mathrm{f}} / \mathrm{SiC}$ composites with pyrocarbon interlayer are of prime interest for the fuel cladding in the Gas-cooled Fast Reactor (GFR). Although the working atmosphere is helium in these advanced reactors, presence of oxidizing impurities could have a significant role on the mechanical behavior of materials for a long time exposure. Within this framework, this study is intended to investigate the influence of oxidation on the $\mathrm{SiC}_{\mathrm{f}} / \mathrm{SiC}$ composites mechanical properties. Different pre-damage states were intentionally operated by mechanical tensile tests on plate specimens before performing an oxidation treatment of 1000 hours at $1000^{\circ} \mathrm{C}$ under helium with $10 \mathrm{ppm}$ of $\mathrm{O}_{2}$. The degradation of the composite was determined from the mechanical behavior of post-exposure specimens. Results were correlated both with microstructural observations of the damaged tows and with characterizations of the generated oxides at the surface of the composites. The most severe decline of mechanical properties occurs for the higher predamaged loadings. A degradation mechanism, depending on the damage state, is proposed to explain the mechanical behavior change in accordance to the different examinations.
\end{abstract}

Keywords: $\mathrm{SiC}_{\mathrm{f}} / \mathrm{SiC}$ composite, Oxidation, Mechanical behaviour, Fiber/matrix bond

\section{INTRODUCTION}

Silicon carbide fiber-reinforced composites $\left(\mathrm{SiC}_{\mathrm{f}} / \mathrm{SiC}\right)$ are considered attractive for applications to nuclear services for their outstanding features including elevated temperature, strength, chemical inertness, stability in irradiation environments and corrosion resistance [1,2]. Over the past decade, significant progress has been made towards both the manufacturing process and the development of what is now considered as a nuclear grade composite, composed of high purity and dense fibers, CVI-SiC matrix with a pyrolitic carbon (PyC) interlayer $[3,4]$. 
The recent progress confirms the potential of innovation for these composites as cladding materials for the next generation of fission nuclear reactor, particularly for the Gas-cooled Fast Reactor (GFR) that is referred in the present study. However, although the working atmosphere is helium, presence of oxidizing impurities could have a significant role on the mechanical holding of materials for a long exposure duration. The oxidation of the pyrocarbon coating that confers on the composite a damage-tolerant behavior could occur and lead to interfacial degradations resulting in a decrease of the mechanical properties [5].

In high temperature environments under helium atmosphere, it has been determinate that the active oxidation of SiC is possible above $1000^{\circ} \mathrm{C}$ from low partial pressures in oxidizing species such as oxygen $\mathrm{O}_{2}\left(\mathrm{P}_{\mathrm{O} 2}<10^{-1} \mathrm{~Pa}\right)[6]$. In this regime, a gaseous oxide is formed according to the reaction (1) that results in a mass loss. In contrast, if the oxidant partial pressure is high enough, a paralinear oxidation of $\mathrm{SiC}$ occurs to form a homogenous and protective layer of silica $\left(\mathrm{SiO}_{2}\right)$ on the surface material, according to the two reactions (2) and (3).

$$
\begin{aligned}
5 i C_{(g)}+O_{2(g)} & =5 i O_{(g)}+C O_{(g)} \\
5 i C_{(g)}+\frac{3}{2} O_{2(g)} & =5 i O_{2(g)}+C O_{(g)} \\
5 i C_{(g)}+2 O_{2}(g) & =5 i O_{2(g)}+C O_{2}(g)
\end{aligned}
$$

The passive regime is of particular interest to protect the $\mathrm{PyC}$ weak interphase against oxidation. In such a condition, a consummated part of the incoming oxygen is expected which has the effect to limit the access to the interphase by sealing the matrix microcracks with a $\mathrm{SiO}_{2}$ oxide phase.

This study is intended to evaluate the influence of the oxidation on the $\mathrm{SiC}_{\mathrm{f}} / \mathrm{SiC}$ composites mechanical properties, subjected to GFR environment in normal temperature range at atmospheric pressure. Different pre-damage states were intentionally operated by tensile testing plate specimens before performing an oxidation treatment of 1000 hours at $1000^{\circ} \mathrm{C}$ under helium with $10 \mathrm{ppm}$ of $\mathrm{O}_{2}$. Post-exposure mechanical tests were performed at room temperature to investigate the effect of corrosion on the ultimate tensile properties.

\section{MATERIALS AND TEST SPECIMENS}

The composite material investigated was chemically vapor-infiltrated $\mathrm{SiC}$ matrix and reinforced with interlock woven fabric (2.5D, contexture: 30 yarns/cm in warp direction, 40 yarns/cm in weft direction). Hi-Nicalon ${ }^{\mathrm{TM}} \mathrm{Type}^{\mathrm{S}}$ $\mathrm{SiC}$ fibers were used; the composite was manufactured by CEA-Saclay (DEN/DMN). A single PyC interlayer was deposited with thickness less than $100 \mathrm{~nm}$. The fiber volume fraction, as reported by the composite manufacturer, is $32 \%$. A representative polished cross-section of the composite is shown in figure 1.

Six test specimens were machined from two composite plates so that the loading direction was parallel to one of the fiber orientations (weft direction). The geometry was rectangular, dimensions of the specimen's gauge section were $180 \mathrm{~mm}(\mathrm{l}) \times 23 \mathrm{~mm}(\mathrm{w}) \times 1,5 \mathrm{~mm}(\mathrm{t})$.

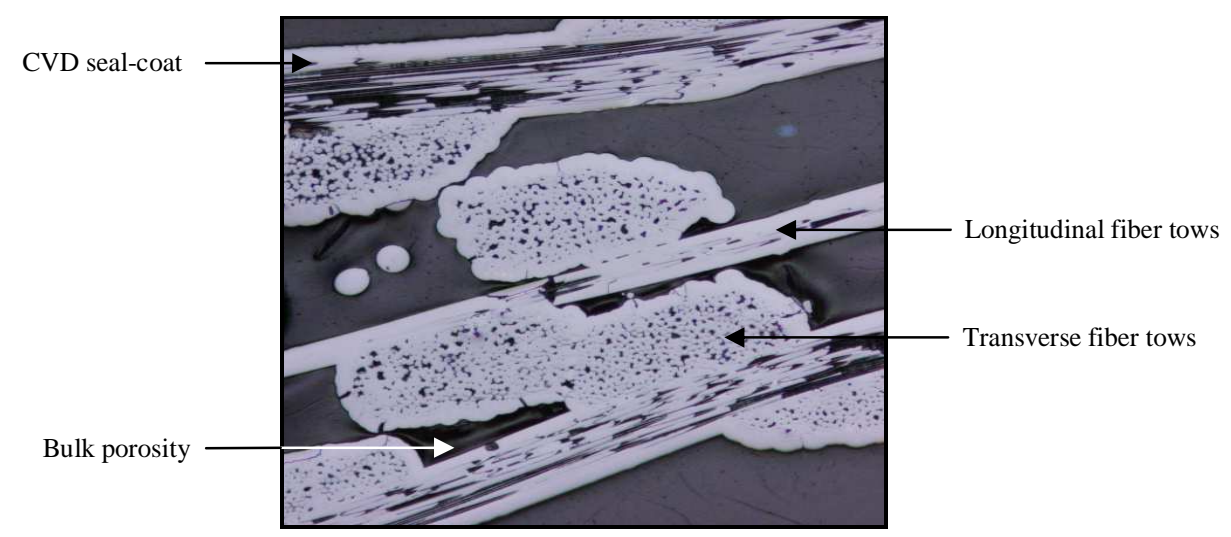

FIGURE 1. Polished cross-section of the as-received $\mathrm{SiC}_{\mathrm{f}} / \mathrm{SiC}$ composite 


\section{TESTS PROCEDURES}

\section{Pre-Damage}

The plate specimens were monotonically loaded in tension at room temperature (RT) into various stresses corresponding to different damaged states of interest in regard to the stress-strain curves obtained on the as received material. The aim of the pre-damage is to generate a controlled microcracks network in the matrix, thus facilitating the ingress of the oxidizing species.

\section{Corrosion Tests}

Oxidation tests were carried out on the CORINTH experimental set-up (CEA Saclay, DEN/DPC) during 1000 hours at the constant temperature of $1000^{\circ} \mathrm{C}$. Four specimens were exposed in a quartz tube reactor to the flowing gas $\left(100 \mathrm{NL} / \mathrm{h}\right.$ ) composed of helium with $10 \mathrm{ppm}$ of $\mathrm{O}_{2}$ (fig. 2). They were heated at a rate of $5^{\circ} \mathrm{C} / \mathrm{min}$ under pure helium, the total pressure inside the furnace was maintained at $1.25 \mathrm{bar}$. At the quartz tube outlet, the concentration of the oxygen as well as the formed gases was analysed all along the treatment by Gas Phase Chromatography (CPG) with helium detector.

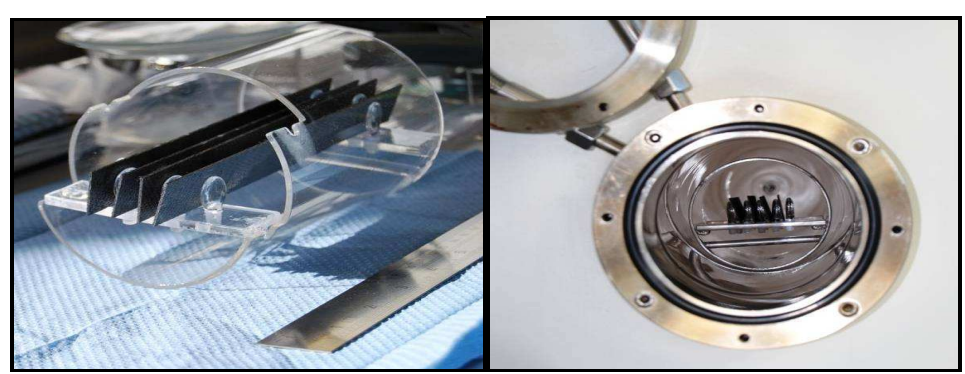

FIGURE 2. View of the corrosion test facility with specimens

\section{Characterization of Specimens after Exposure}

Post-exposure cyclic tensile tests were performed on the plate specimens at CEA Grenoble (LITEN/DTBH). The composites were tested up to failure at RT in a servo-hydraulic testing machine (INSTRON) equipped with self aligning grips at a cross-head speed of $0.1 \mathrm{~mm} / \mathrm{min}$. Longitudinal deformations were measured using both extensometer mounted on a lateral face (gauge length: $25 \mathrm{~mm}$ ) and eight strain gauges $\left(0^{\circ} / 45^{\circ} / 90^{\circ}\right)$ stuck on the front and rear faces. The residual strains, the opening of the cycles and the damage progression were extracted from the experimental curves and exploited to give information about the state of the fiber-matrix bond.

After mechanical testing, polisher cross sections were prepared perpendicularly and parallel to the loading direction for examinations using an optical and scanning electron microscope (OM, SEM), as well as the fractured surfaces by SEM. Finally, the thickness and the chemical composition of the oxide phase formed at the composite surface were determined using respectively Auger electron spectroscopy (AES) and X-ray photoelectron spectroscopy (XPS).

AES measurements were made on a VG MICROLAB 310-F apparatus equipped with a field emission gun and an $\mathrm{Ar}^{+}$ion sputtering gun for depth profiling. The variation of the intensities of the Auger electron peaks (KLL transition) as a function of the sputtering time was used to plot the semi-quantitative composition-depth profile from the sample surface.

XPS analyses were achieved with a VG Scientific 220 i-XL ESCALAB spectrometer. The X-Ray source was a monochromatized AlK $\alpha$ radiation with an energy of $1486,6 \mathrm{eV}$ at $70 \mathrm{~W}$. A pressure of $10^{-7} \mathrm{~Pa}$ was maintained in the chamber during analysis. The spot size was around $180 \mu \mathrm{m}$ in diameter. The full spectrum $(0-700 \mathrm{eV})$ was obtained with a constant pass energy of $150 \mathrm{eV}$ and high resolution spectra at a constant pass energy of 20eV. Charge neutralization was required when insulating samples were detected. $\mathrm{An} \mathrm{Ar}^{+}$ion gun was used to sputter specimen surfaces at low speed rate namely $0.2 \mathrm{~nm} / \mathrm{s}$. High resolution spectra were fitted and quantified using the AVANTAGE software provided by ThermoFisher Scientific. 


\section{RESULTS}

\section{The Post-Exposure Mechanical Results}

Two specimens were used to determine the mechanical properties up to failure for the as-received materials. The results of mechanical testing are reported in table 1. For all samples, the failures occurred in the gauge section that proves the relevance of the tests, including a good alignment for specimens.

Figure 3 shows the typical obtained stress-strain curves which evidence several features. The shape of curves between the as-received materials and the treated specimens is similar. Thus, a non linear stress-strain behavior without a plateau is observed up to the ultimate failure. According to this behavior induced by matrix cracking, a continuous damage occurred in the composite up to its failure.

The width of the hysteresis loops is narrow and the residual strains after unloading are very low which is characteristic of a high fiber-matrix load transfer and a strong interfacial shear stress.

Moreover, the results of post-exposure mechanical tensile testing allow to highlight a decrease of the stress and strain to failure from the composite that seems to be linked to the pre-damage stress, as soon as it is higher than about $118 \mathrm{MPa}$.

TABLE 1. Summary of tensile properties at RT for the as-received and post-exposure specimens

\begin{tabular}{lllll}
\hline Test condition & Tensile test & UTS (MPa) & Strain to failure (\%) & E (GPa) \\
\hline As received & Cyclic & $\mathbf{3 0 6}$ & $\mathbf{0 , 3 9}$ & $\mathbf{1 9 9}$ \\
Oxidize-OMPa & Cyclic & 258 & 0,29 & 228 \\
Oxidize-118MPa & Cyclic & 269 & 0,30 & 174 \\
Oxidize-173MPa & Cyclic & 286 & 0,25 & 218 \\
Oxidize-270MPa & Cyclic & 232 & 0,18 & 184 \\
\hline
\end{tabular}

(a)

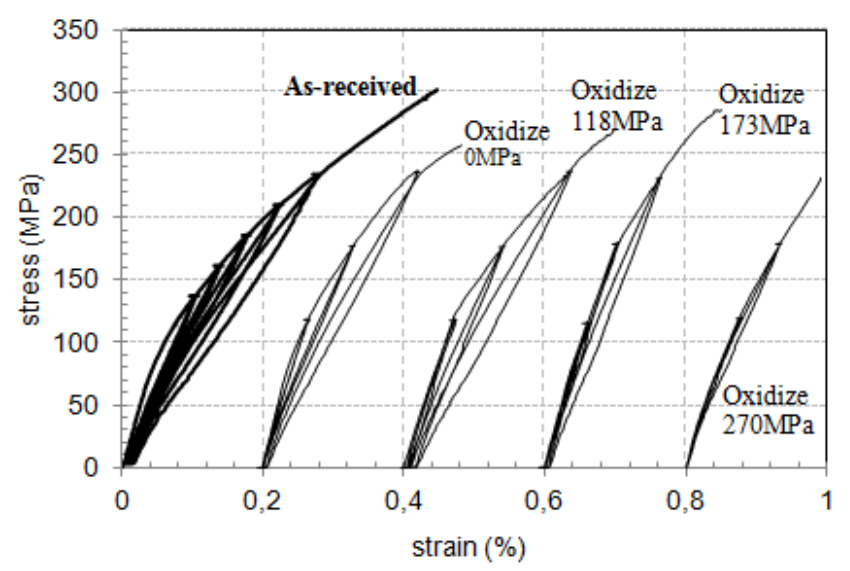

(b)

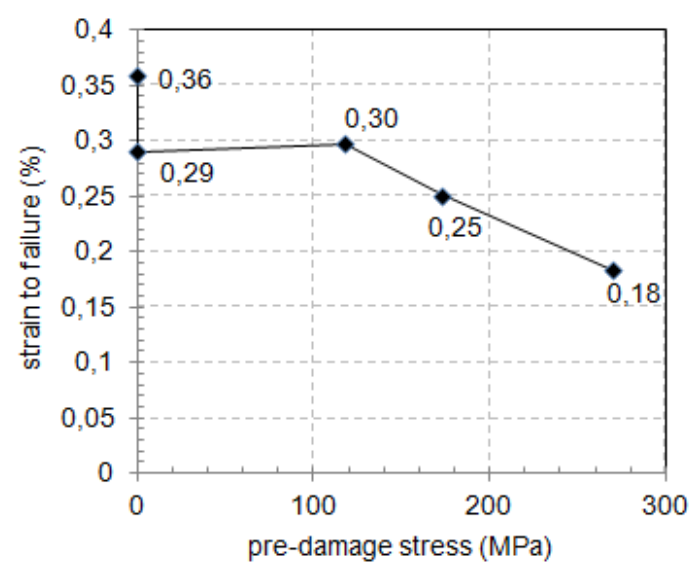

FIGURE 3. Representation of the Stress-strain curves of the $\mathrm{SiC}_{\mathrm{f}} / \mathrm{SiC}$ composite specimens obtained at $\mathrm{RT}$ after oxidation treatment (a) and the evolution of the residual strain versus the pre-damage stress (b)

In order to describe the damage progression, the variation of the elastic modulus is measured from the slope of the tangent at the origin on the different stress-strain curves at each of the load-unload loops (fig. 4). Whatever the material, the elastic moduli decreased gradually during the test up to the ultimate failure. On these diagrams, it is instructive to compare the initial modulus of the aged composites with those of the healthy as-received materials. Thus, the exposed materials have an initial modulus similar or higher than the modulus of the as-received material. The result is consistent with the sealing of the pre-damage cracks with a silica oxide phase. 

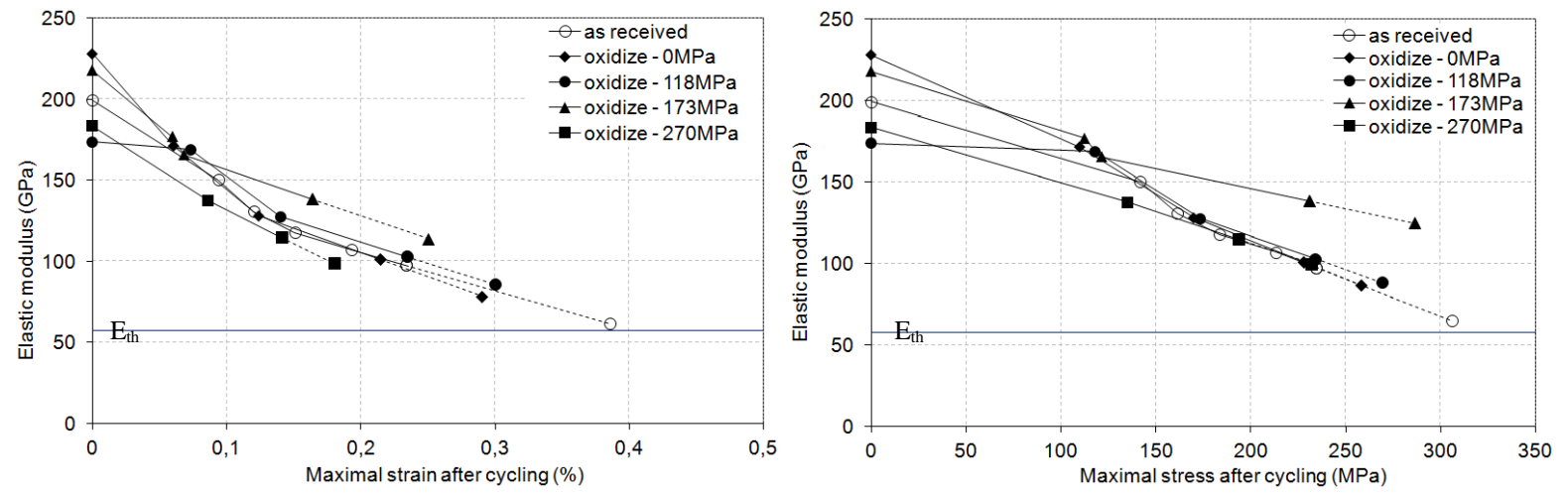

FIGURE 4. Damage progression of $\mathrm{SiC}_{\mathrm{f}} / \mathrm{SiC}$ specimens during tensile cycling at $\mathrm{RT}$ after exposures at $1000^{\circ} \mathrm{C}$ for 1000 hours under helium with $10 \mathrm{ppm}$ of $\mathrm{O}_{2}$
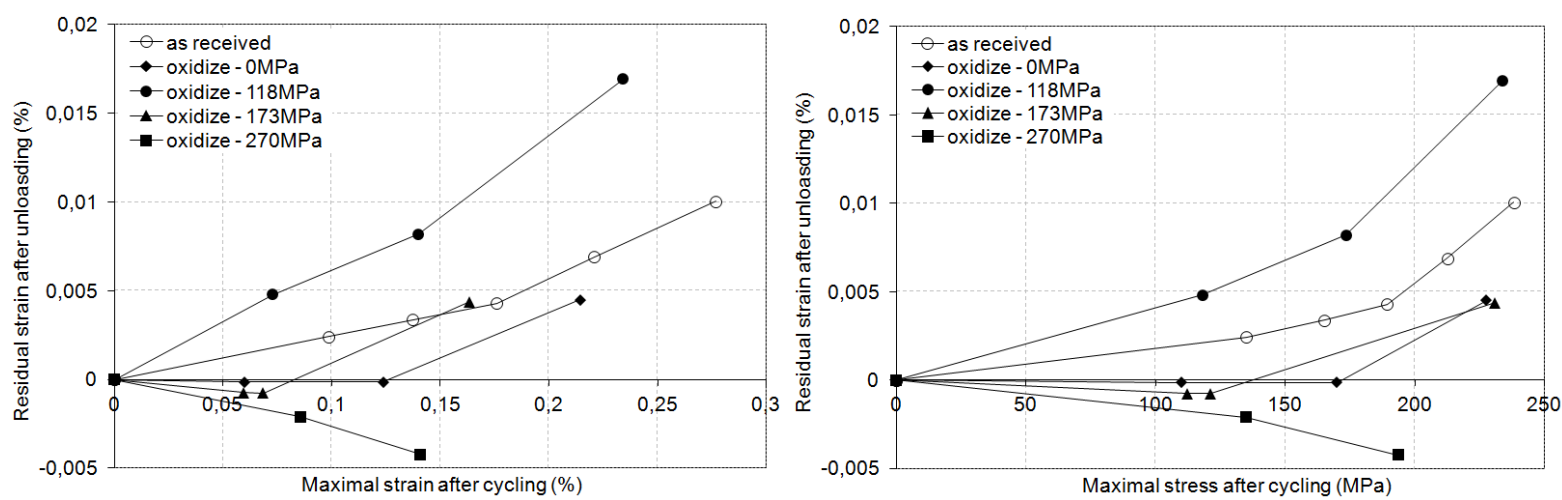

FIGURE 5. Variation of the residual strain after unloading of $\mathrm{SiC}_{\mathrm{f}} / \mathrm{SiC}$ specimens during tensile cycling at RT after exposures at $1000^{\circ} \mathrm{C}$ for 1000 hours under helium with $10 \mathrm{ppm}$ of $\mathrm{O}_{2}$
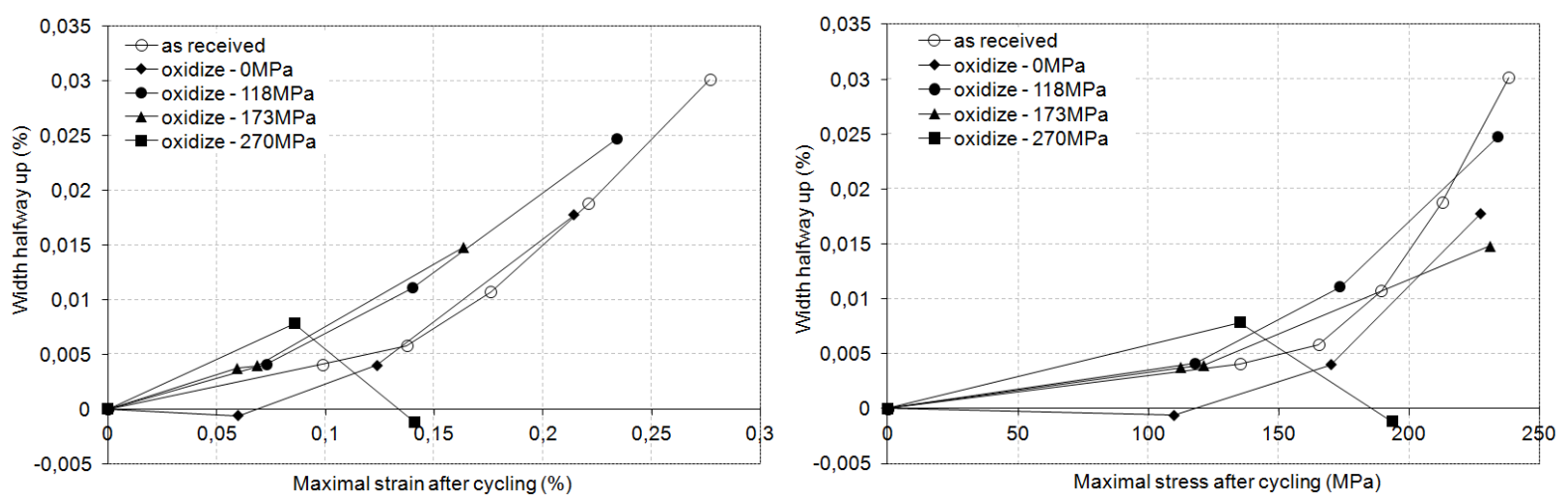

FIGURE 6. Variation of the width halfway up of the hysteresis loops after unloading of $\mathrm{SiC}_{\mathrm{f}} / \mathrm{SiC}$ specimens during tensile cycling at $\mathrm{RT}$ after exposures at $1000^{\circ} \mathrm{C}$ for 1000 hours under helium with $10 \mathrm{ppm}$ of $\mathrm{O}_{2}$ 
Nevertheless, when the pre-damage becomes significant (beyond $118 \mathrm{MPa}$ in the present study), increasing the predamage stress leads to a decrease of the modulus of the aged composites faster than for the as-received material. This corresponds to a faster damage progression, certainly associated to local brittle ruptures of a few tows that results in a premature failure.

The modulus values at failure, determinate using a linear extrapolation (horizontal line in Fig. 4) are compared with the theoretical modulus at failure $\mathrm{E}_{\mathrm{th}}$ of a $2,5 \mathrm{D}$ woven composite. It is calculated from the relation (4), considering that only the fibers oriented in the loading direction (weft direction), load-bearing:

$$
E_{\text {zh }}=\frac{40}{(40+\pi 0)} * E_{f} * V_{f}
$$

where $\mathrm{E}_{\mathrm{f}}$ is the fiber modulus at RT (Hi-Nicalon ${ }^{\mathrm{TM}}$ type $\mathrm{S}$ fiber: $315 \mathrm{GPa}$ ) and $\mathrm{V}_{\mathrm{f}}$ is the fiber volume fraction (32\%). The extrapolated moduli remain significantly higher than the theoretical modulus $\mathrm{E}_{\mathrm{th}}$, consolidating the assumption that the damage progression is not complete, as well for the as-received, as the aged composite.

According to previous works [7], the variations of residual strains and the width halfway up of the hysteresis loops are then extracted from the mechanical curves after each unloading. The residual strains increase similarly for the as-received and the aged composite with a low pre-damage (fig. 5). The same evolution is shown in figure 6 for the hysteresis loop. This result seems to indicate that the fiber-matrix bond of the composites is not significantly affected. Despite the presence of cracking, the matrix could provide a protection to the PyC interlayer. Consequently, the fiber-matrix load transfer remains efficient.

On the other hand, a difference of behavior between the strongly pre-damaged and the others is highlighted in the figures 5 and 6 . The opening of the unloading/loading hysteresis loop is comparatively found negative; the trend is enhanced with the second loop. The evolution of the residual strain after unloading is also reverse to that expected. A very rough fiber or matrix surface due to the formation of silica could perturb the free sliding of debonded fibers embedded into the matrix. A kind of spring should act on the fiber to force its replacement in its initial position.

\section{Post-Exposure Observations}

All the mechanically tested materials exhibit a non-brittle surface rupture characterized by fiber pull out (fig.7a). However, it was noted in the exposure conditions specific to the furnace that oxidation seems to occur firstly at the edge of the composite: silica bonds the fiber to the matrix and brittle surfaces are locally observed with no pull out (fig.7b). In the same order, SEM observations of the higher pre-damaged specimen exhibit many tows with a brittle failure surface (fig.7c).

(a)

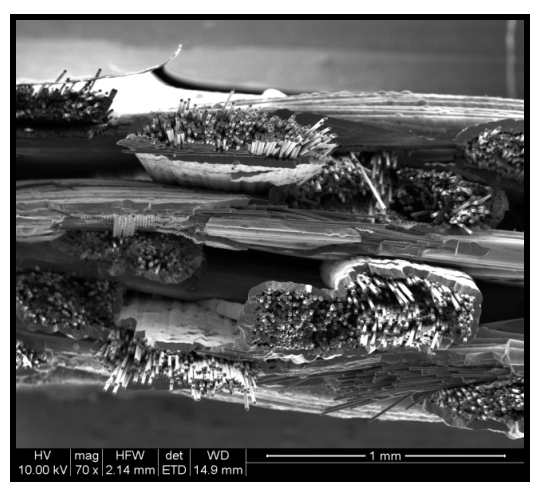

(b)

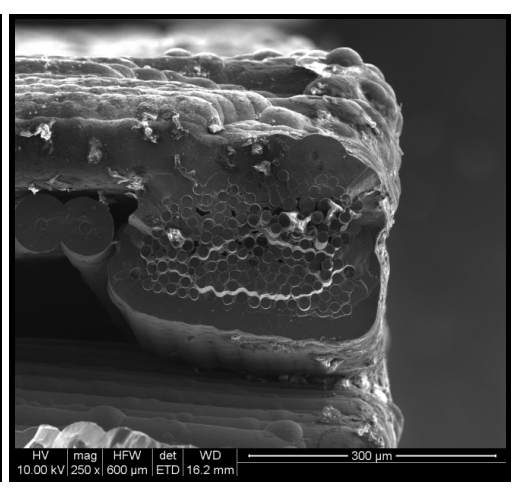

(c)

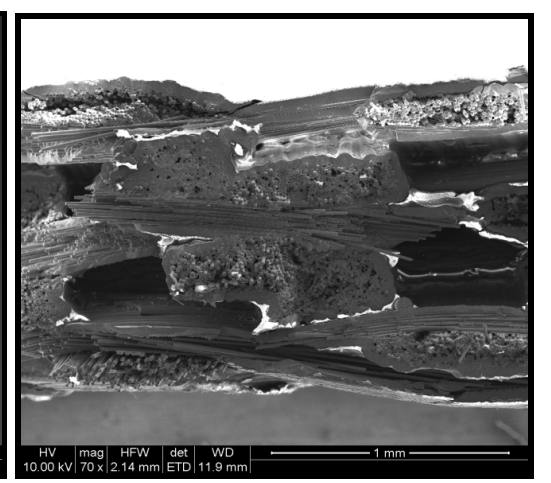

FIGURE 7. SEM representative fractured surface of the $\mathrm{SiC}_{\mathrm{f}} / \mathrm{SiC}$ specimen exposed for 1000 hours at $1000^{\circ} \mathrm{C}$ under helium with $10 \mathrm{ppm}$ of $\mathrm{O}_{2}$ for as-received material (a), (b) and higher pre-damaged composites (c) 
The conclusion of SEM examinations reveals that the higher the pre-damaged loading is, the more important is the embrittlement: the failure surface becomes smoother with shorter fiber pull-out lengths. Reversely, the self-healing process well known for the $\mathrm{SiC}_{\mathrm{f}} / \mathrm{SiC}$ composite materials seems to be more efficient for thinner matrix cracks, created at lower pre-damaged loadings.

\section{Characterization of the oxides}

The XPS analysis confirms the passive oxidation regime for the oxidation treatment. A characteristic peak corresponding to the silica formed on the surface of the composite is observed. The Si $2 \mathrm{p}_{3 / 2-1 / 2}$ photoelectron peak collected for the oxidizing materials is shown in figure 8a. The components located at 103.5-104.1 eV were attributed to $\mathrm{Si}-\mathrm{O}$ bonds in $\mathrm{SiO}_{4}$ silica compound and the components located at 102.3-102.9 eV to Si-O bonds in Si$\left(\mathrm{O}_{2} \mathrm{C}_{2}\right)$ compounds.

The oxide thickness measured from AES atomic depth profile (fig. 8b) is around $40 \mathrm{~nm}$ for the $1000^{\circ} \mathrm{C}, 1000 \mathrm{~h}, \mathrm{He}-$ $10 \mathrm{ppm} \mathrm{O}_{2}$ oxidized sample. A surface contamination is observed in the first atomic layer.

(a)

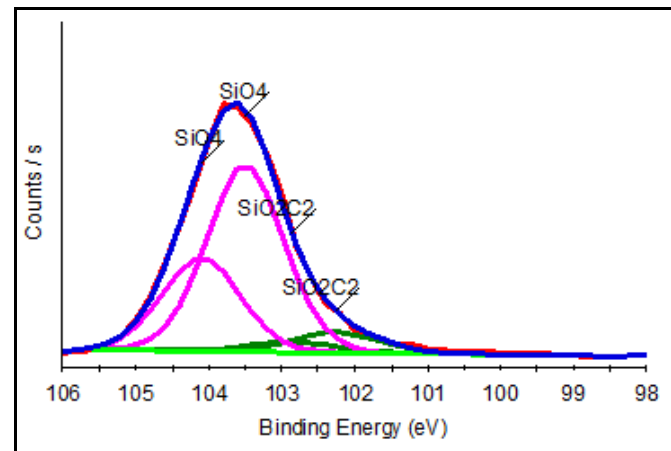

(b)

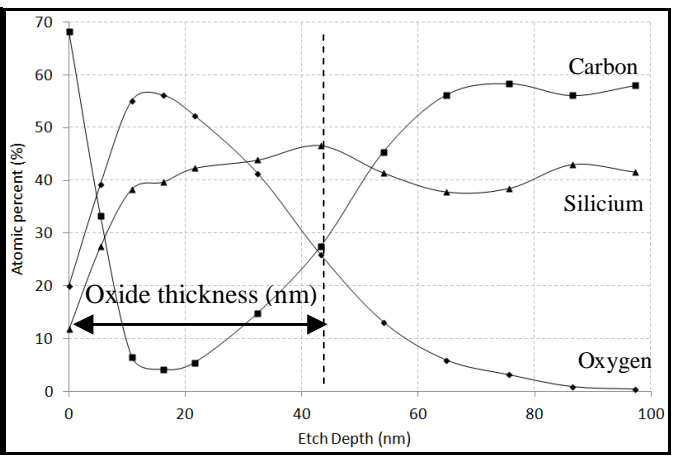

FIGURE 8. Surface chemistry analysis of the oxidizing materials at $1000^{\circ} \mathrm{C}$ for 1000 hours under helium with 10 ppm of $\mathrm{O}_{2}$ : (a) XPS high resolution spectra and (b) AES atomic depth profile

\section{DISCUSSION}

The measurements of the post exposure mechanical properties after corrosion test at $1000^{\circ} \mathrm{C}$ for 1000 hours under helium with $10 \mathrm{ppm}$ of $\mathrm{O}_{2}$ reveal that the $\mathrm{SiC}_{\mathrm{f}} / \mathrm{SiC}$ composite mechanical behavior is affected. The strain to failure, the ultimate stress and the damage progression are modified. Also, the strain to failure of the composite decreases as much as the pre-damage is important. According to these results, a degradation of the fiber-matrix bond is highlighted.

Two scenarios were considered to explain the oxidation progression through a pre-damaged crack in the $\mathrm{SiC}$ matrix. A schematic mechanism, based on the silica formation on the surface of the oxidizing composites, is depicted in figure 9. When the pre-damage is performed at a low stress level, a few minor matrix cracks are created with a slight opening (fig.9a). So, during the relaxation of the stress, cracks close up that contribute to prevent the diffusion of oxygen into the bulk of the material. Assuming that the oxidation reaction of the $\mathrm{SiC}$ matrix occurs, the formed silica fills the pre-existent cracks and seals the material.

In contrast, we explain the early failure observed for the high pre-damaged composites in comparison to the asreceived ones by a local consumption of the Pyrocarbon interlayer in front of cracks (fig. 9b). In this case, both the distribution and the width of cracks are increased making impossible the complete closing during the relaxation of stresses. As a consequence, oxidizing species can reach by diffusion up to the core of the composite. The silica content formed does not seem to be sufficient to form a cork and to be able to seal cracks. It locally results in a chemical degradation of the PyC interlayer and fibers.

The degradation mechanisms are in good agreement with results from a recent study conducted at CEA Saclay, emphasizing the dependence of the crack propagation with loading for $\mathrm{CVI}-\mathrm{SiC} / \mathrm{SiC}$ minicomposites [8]. 

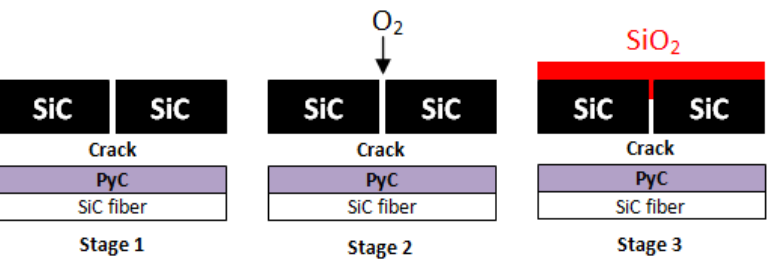

(a)

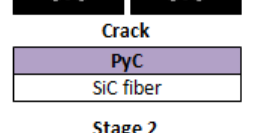

Stage 3

(b)

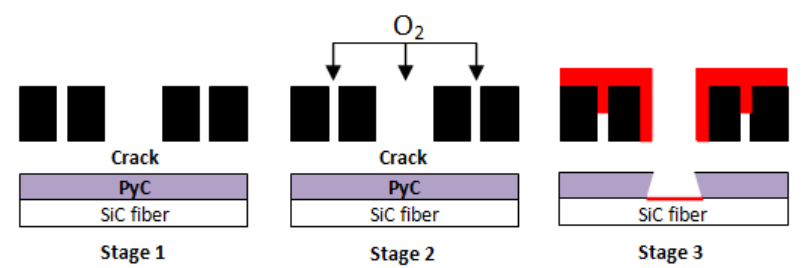

FIGURE 9. Proposed oxidation process after ageing at $1000^{\circ} \mathrm{C}$ for 1000 hours at atmospheric pressure under helium with $10 \mathrm{ppm}$ of $\mathrm{O}_{2}$ for: (a) lowly pre-damaged composites and (b) highly pre-damaged composites

\section{CONCLUSION}

This study is part of the $4^{\text {th }}$ generation program research of cladding materials for fission nuclear reactors, particularly the Gas-cooled Fast Reactor (GFR). The aim of this study was to investigate the influence of oxidation on the $\mathrm{SiC}_{\mathrm{f}} / \mathrm{SiC}$ composites mechanical properties. After ageing in an oxidizing environment during 1000 hours at $1000^{\circ} \mathrm{C}$ under helium with $10 \mathrm{ppm}$ of $\mathrm{O}_{2}$, the mechanical properties are found affected. The decrease of the strain to failure is particularly significant for composites having undergone an important pre-damage. Local embrittlements were observed on fracture surfaces, highlighted by flat breaking surface and failure of tows with no pull out.

In contrast, the corrosion-resistance capability of the $\mathrm{SiC}_{\mathrm{f}} / \mathrm{SiC}$ composites is maintained when the pre-damage is low. In this case, the limitation of the diffusion of oxidizing species through the cracks network is related to the consumption of the $\mathrm{SiC}$ matrix to form a protective silica oxide phase. The PyC interlayer is no more attacked: a good retention of mechanical properties is preserved.

\section{Acknowledgments}

This work has been supported by CEA through a training course grant to E. Torres. The authors are grateful to M. Lahaye for the realisation of AES analyses and C. Labrugere for the XPS analyses.

\section{References}

1. Y. Katoh, T. Nozawa, L.L. Snead, K. Ozawa, H. Tanigawa, Journal of Nuclear Materials 417, 400-405 (2011).

2. LL. Snead, T. Nozawa, Y. Katoh, T.S. Byun, S. Kondo, D.A. Petti, Journal of Nuclear Materials 371, 329-377 (2007).

3. C. Lorrette, C. Sauder, L. Chaffron, $18^{\text {th }}$ International Conference on Composite Materials, Conference Proceeding, South Korea, Jeju Island (2011).

4. E. Buet, C. Sauder, S. Poissonnet, P. Brender, R. Gadiou, C. Vix-Guterl, Journal of the European Ceramic Society 32, 547-557 (2012).

5. L. Filipuzzi, "Oxydation des composites SiC/SiC et de leurs constituants: approche expérimentale, modélisation et influence sur le comportement mécanique », Ph.D Thesis, University of Bordeaux (1991).

6. J. Eck, M. Balat-Pichelin, L. Charpentier, E. Bêche, F. Audubert, Journal of the European Ceramic Society 28, 2995-3004 (2008).

7. J.Lamon, F. Rebillat, A. Evans, Journal of the Am. Cer. Soc. 78 [2], 401-405 (1995).

8. C. Chateau, L. Gelebart, M. Bornert, J. Crépin, E. Boller, C. Sauder, W. Ludwig, «In situ X-ray microtomography characterization of damage in $\mathrm{SiC}_{\mathrm{f}} / \mathrm{SiC}$ minicomposites », Composites Science and Technologiy 71, 916-924 (2011). 